Supporting Information for

\title{
Small Pore Aluminosilicate EMM-37: Synthesis and Structure Determination using Continuous Rotation Electron Diffraction
}

Elina Kapaca ${ }^{\dagger}$ Allen Burton, ${ }^{\S}$ Eugene Terefenko,${ }^{\S}$ Hilda Vroman, ${ }^{\S}$ Simon C. Weston, ${ }^{\S}$ Meghan Kochersperger,${ }^{\S}$ Mobae Afeworki, ${ }^{\S}$ Charanjit Paur, ${ }^{\S}$ Lucas Koziol,,${ }^{\circledR}$ Peter Ravikovitch,${ }^{\S}$ Hongyi Xu, ${ }^{\dagger}$ Xiaodong Zou, ${ }^{\dagger}$ Tom Willhammar*†

${ }^{\dagger}$ Berzelii Center EXSELENT on Porous Materials, Department of Materials and Environmental Chemistry, Stockholm University, SE-106 91 Stockholm, Sweden.

§ExxonMobil Research and Engineering Company, 1545 Route 22 East, Annandale, NJ 08801, USA. 


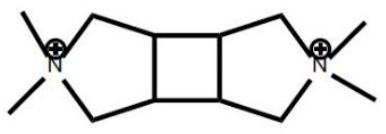

SDA for ITQ-32

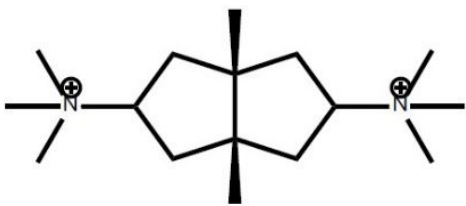

SDA for ITQ-55

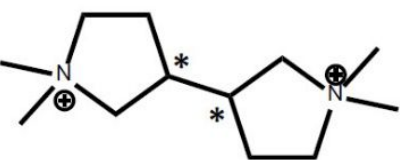

SDA for EMM-37

(RS isomer)

Figure S1. Structure directing agents (SDAs) used to synthesize the three materials ITQ-32, ITQ-55 and EMM-37, respectively.

\section{Synthesis description of diimide, diamine and diquaternary ammonium, isomer separation, ${ }^{13} \mathrm{C}$ Dept NMR spectra}

The diimide (3R,3'S)-1,1'-dimethyl-3,3'-bipyrrolidine-2,2',5,5'-tetraone was prepared by reacting 1.6 equivalent methylamine with 1 equivalent of the dianhydride meso-butane-1,2,3,4-tetracarboxylic anhydride in a microwave by using a 15 -minute ramp to $160^{\circ} \mathrm{C}$ and maintaining the temperature at $160{ }^{\circ} \mathrm{C}$ for 1 hour. Water was used as the solvent. After microwaving, the reaction mixture was dripped into methanol $(\sim 10 \mathrm{~mL}$ $\mathrm{MeOH} / 1 \mathrm{~g}$ mesobutane-1,2,3,4-tetracarboxylic anhydride). After 5-10 min, a white solid was formed which was isolated on a frit and oven-dried. The white crystalline solid (56\% yield) was pure diimide by ${ }^{1} \mathrm{H}$ NMR.

The diimide 1,1-dimethyl-3,3'-bipyrrolidine-2,2',5,5'-tetraone was reduced to a diamine using the following procedure. Within a 3-L, 3-necked round bottom flask, $16.89 \mathrm{~g}$ of lithium aluminum hydride (LAH) in pellet form was added to $1500 \mathrm{~mL}$ tetrahydrofuran and the suspension was mixed vigorously overnight. $31.56 \mathrm{~g}$ diimide was added gradually to the stirring mixture in 5-g increments over the course of about 2 hours while keeping the flask cooled in an ice bath. After stirring it overnight, a heating mantle was placed underneath the flask, and the suspension was then refluxed for 2 hours. The flask was then cooled in an ice bath and about $400 \mathrm{ml}$ diethyl ether was added to the mixture. At this point $200 \mathrm{~mL}$ of $45 \% \mathrm{NaOH}$ solution was then added dropwise under vigorous stirring. After the grey solids became white, the solids were removed by filtration and the THF/ether layer was isolated using a separatory funnel. The solution was then dried with anhydrous magnesium sulfate and the solids were then removed by filtration. The diamine was then recovered by rotoevaporation to obtain $63 \%$ yield of product. ${ }^{1} \mathrm{H}$ NMR and ${ }^{13} \mathrm{C}$ NMR showed the product to be about a $60 / 40$ mixture of the two isomers.

The diamine was converted to a diquaternary ammonium molecule as follows. To $300 \mathrm{~mL}$ methanol was added $51.92 \mathrm{~g}$ diamine. Next $132 \mathrm{~g}$ iodomethane was added dropwise with vigorous stirring. The next day, the solid precipitate was isolated by filtration. ${ }^{1} \mathrm{H}$ (bottom of Figure S2) and ${ }^{13} \mathrm{C}$ NMR (bottoms of Figure S3 and Figure S4) showed the product to be $\sim 95 \%$ isomer A. The rest of the product was isolated by rotoevaporation of the solvent. The solid residues from the rotoevaporation were washed with acetone and then dried overnight. ${ }^{1} \mathrm{H}$ (top of Figure S2) and ${ }^{13} \mathrm{C}$ NMR (tops of Figure S3 and Figure S4) showed the product recovered from the solvent to be about $92 \%$ isomer B. The initially recovered solids were further purified by performing two recrystallizations from hot methanol with minimal addition of deionized water. From the recrystallization we obtained large crystals that were used for a structure solution from single crystal $\mathrm{X}$-ray diffraction. From this procedure we obtained $47 \mathrm{~g}$ of the isomer A and $33 \mathrm{~g}$ of the isomer B. A single crystal structure solution showed that isomer A was the RS diastereomer. 


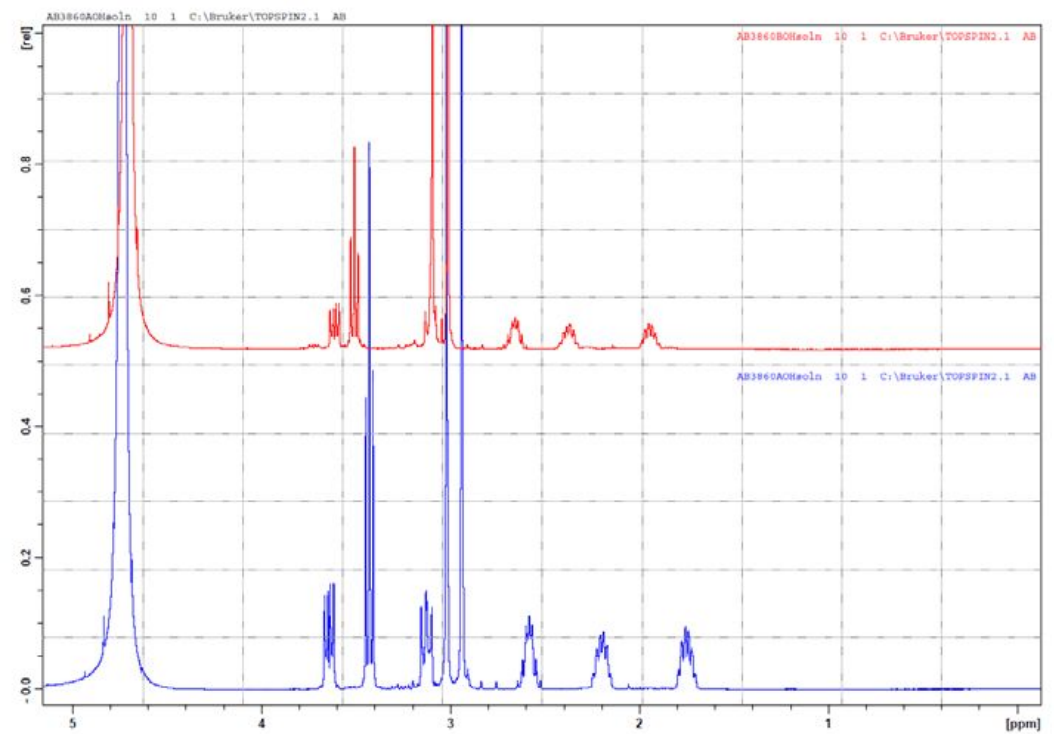

Figure S2 Comparison of ${ }^{1} \mathrm{H}$ NMR spectra of hydroxide solutions of isomer A (bottom) and isomer B (top).

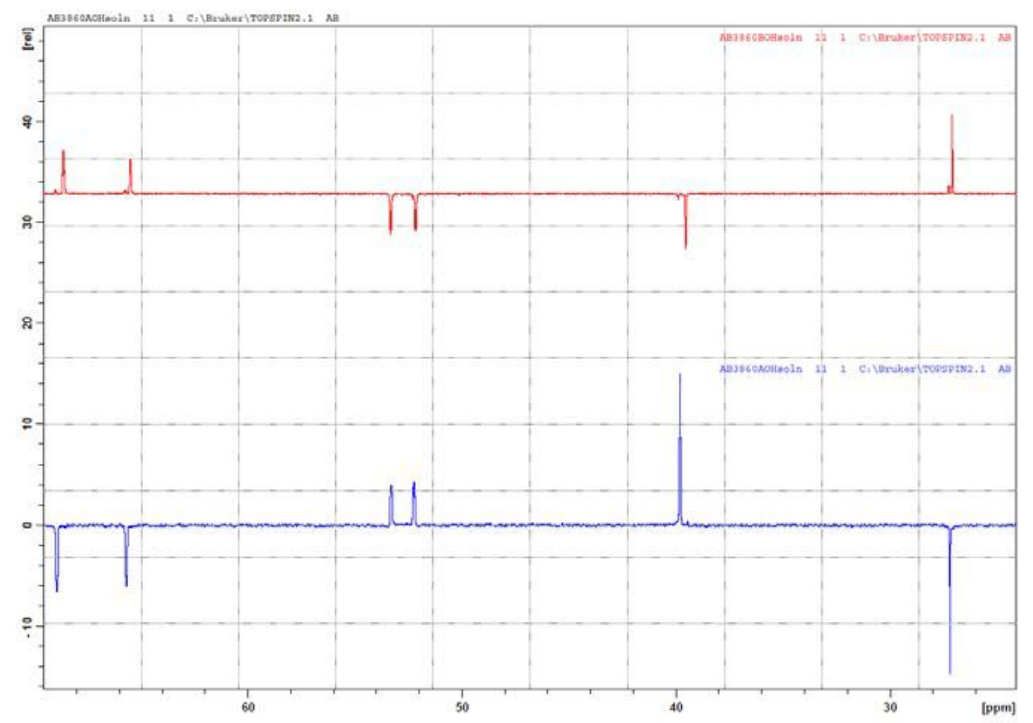

Figure S3 Comparison of ${ }^{13} \mathrm{C}$ Dept NMR spectra of hydroxide solutions of isomer A (bottom) and isomer B (top). For the top spectrum, the signals for carbon atoms with odd numbers of bonded protons are negative and those with even numbers of bonded protons are positive. For the bottom spectrum this is reversed. 


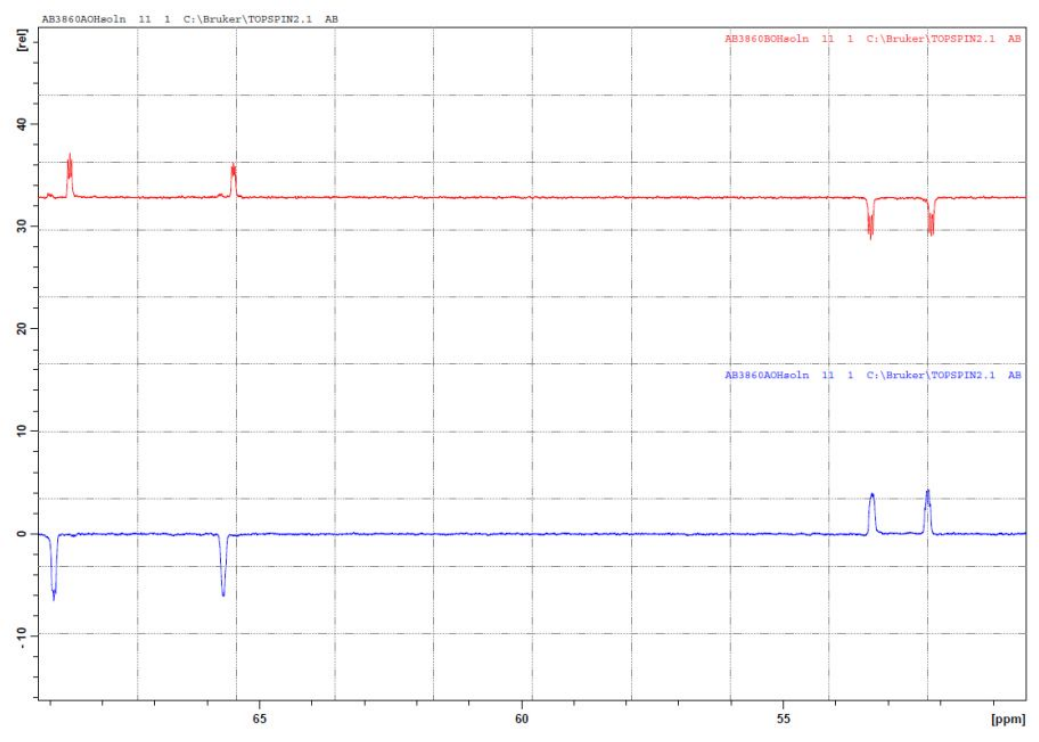

Figure S4 ${ }^{13} \mathrm{C}$ Dept NMR spectra of hydroxide solutions of isomer A (bottom) and isomer B (top) at more narrow range to show splitting of ${ }^{13} \mathrm{C}$ peaks for $\mathrm{C}$ species bonded to $\mathrm{N}$. Note the multiplet splitting for each of the peaks. For the top spectrum, the signals for carbon atoms with odd numbers of bonded protons are negative and those with even numbers of bonded protons are positive. For the bottom spectrum this is reversed.

Isomer A was converted into its hydroxide form by dissolving it in water and adding it to $700 \mathrm{~mL}$ of Dowex LC NG hydroxide. The next day the resin was removed by filtration and washed with deionized water to remove the product from the resin.

The aqueous fractions were then combined and concentrated under reduced pressure at about $60{ }^{\circ} \mathrm{C}$. The hydroxide concentration of this aqueous solution $(1.86 \mathrm{mmol} \mathrm{OH}-/ \mathrm{g})$ was determined by titration with a standard solution of $0.1 \mathrm{~N} \mathrm{HCl}$. Figure $\mathrm{S} 2$ compares the ${ }^{1} \mathrm{H}$ NMR spectra of the hydroxide solutions of isomer $\mathrm{A}$ and isomer B, and Figure S3 and Figure S4 compare the ${ }^{13} \mathrm{C}$ Dept NMR spectra of the same solutions. Note that in the "isomer B" solution, a trace amount of isomer A can also be detected.

Splittings in ${ }^{13} \mathrm{C}$ NMR spectra shown above are due to residual ${ }^{13} \mathrm{C}-{ }^{14} \mathrm{~N}$ quadrupolar couplings. They are not always clearly detected, but when they are, the magnitude of the coupling (JCN) is typically from 3.6 to $3.9 \mathrm{~Hz}$. The residual coupling and the resulting splitting depend on the quadrupolar relaxation of ${ }^{14} \mathrm{~N}$ $\left(\mathrm{T} 1\left({ }^{14} \mathrm{~N}\right)\right)$ which in turn depends on molecular motion (thus, temperature, concentration, solvent choice affect it). ${ }^{1}$ The splitting is better defined for longer quadrupolar relaxation time and at higher concentrations where aggregates can form, the ${ }^{14} \mathrm{~N}$ relaxation times become short, and the splitting becomes more of a broadening. Furthermore, the splitting also depends on the geometry around the ${ }^{13} \mathrm{C}-{ }^{14} \mathrm{~N}$ vector and structures attached to it. For instance, terminal $\mathrm{C}-\mathrm{N}\left(\mathrm{CH}_{3}\right)^{3}$ is less dependent on the ${ }^{13} \mathrm{C}-{ }^{14} \mathrm{~N}$ vector, but strongly depends on what the $\mathrm{C}$ is attached to, which controls mobility, or lack thereof, to greater extent. Residual splitting due to ${ }^{13} \mathrm{C}-{ }^{14} \mathrm{~N}$ quadrupolar couplings are also observed in solid state ${ }^{13} \mathrm{C}$ NMR and magic-angle spinning does not average them out. ${ }^{2}$ However, because quadrupolar interactions are inversely related to magnetic fields, these splittings are better observed at relatively lower magnetic fields. As the field is increased, the residual splitting becomes more of a broadening making clear assignments of ${ }^{13} \mathrm{C}$ NMR difficult, and eventually becoming negligible.

Sample used for structure determination of material after calcination at $540{ }^{\circ} \mathrm{C}$ :

$\mathrm{Si} / \mathrm{Al}=6.7, \mathrm{NaOH} / \mathrm{Si}=0.30, \mathrm{SDA}(\mathrm{OH})_{2} / \mathrm{Si}=0.15$ and $\mathrm{H}_{2} \mathrm{O} / \mathrm{Si}=30$ for 7 days at $160{ }^{\circ} \mathrm{C}$. The material crystallizes as plate-like crystals, see Fig. S5(b). The synthesis was performed in a $1.5 \mathrm{~mL}$ stainless steel reactor with a teflon insert by mixing together the SDA solution, metakaolin, sodium hydroxide solution, deionized water, and Ludox AS-40. After the vessel was sealed, it was heated under tumbling conditions for 
7 days at $160{ }^{\circ} \mathrm{C}$. The solid product was recovered by centrifugation. The solid was then re-dispersed in deionized water, centrifuged, and then the liquid fraction was decanted. This was repeated 3 times to isolate the final product.

Sample used for structure determination of as-made material:

An experiment was performed on a larger scale within a $23-\mathrm{mL}$ Teflon liner. $2.65 \mathrm{~g}$ of the diquat solution

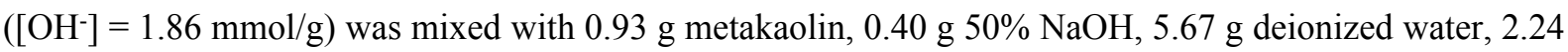
g Ludox AS-40, and $0.053 \mathrm{~g}$ EMM-37 seeds from 585549A4. The Teflon liner was then capped and sealed inside a $23-\mathrm{mL}$ steel Parr autoclave. The autoclave was then heated under tumbling conditions ( $\sim 40 \mathrm{rpm})$ at $160{ }^{\circ} \mathrm{C}$ for 7 days. The product was then recovered by filtration and washed with about $250 \mathrm{~mL}$ deionized water. The material crystallizes as small sheet-like crystals, see Fig. S5(a).

\section{SEM of the material of EMM-37}

Scanning electron microscopy (SEM) images were acquired using a JEOL JSM-7401F microscope with a below the lens (LEI) secondary electron detector and cold FEG system operated at an accelerating voltage of $2 \mathrm{kV}$ and working distance of $8 \mathrm{~mm}$.

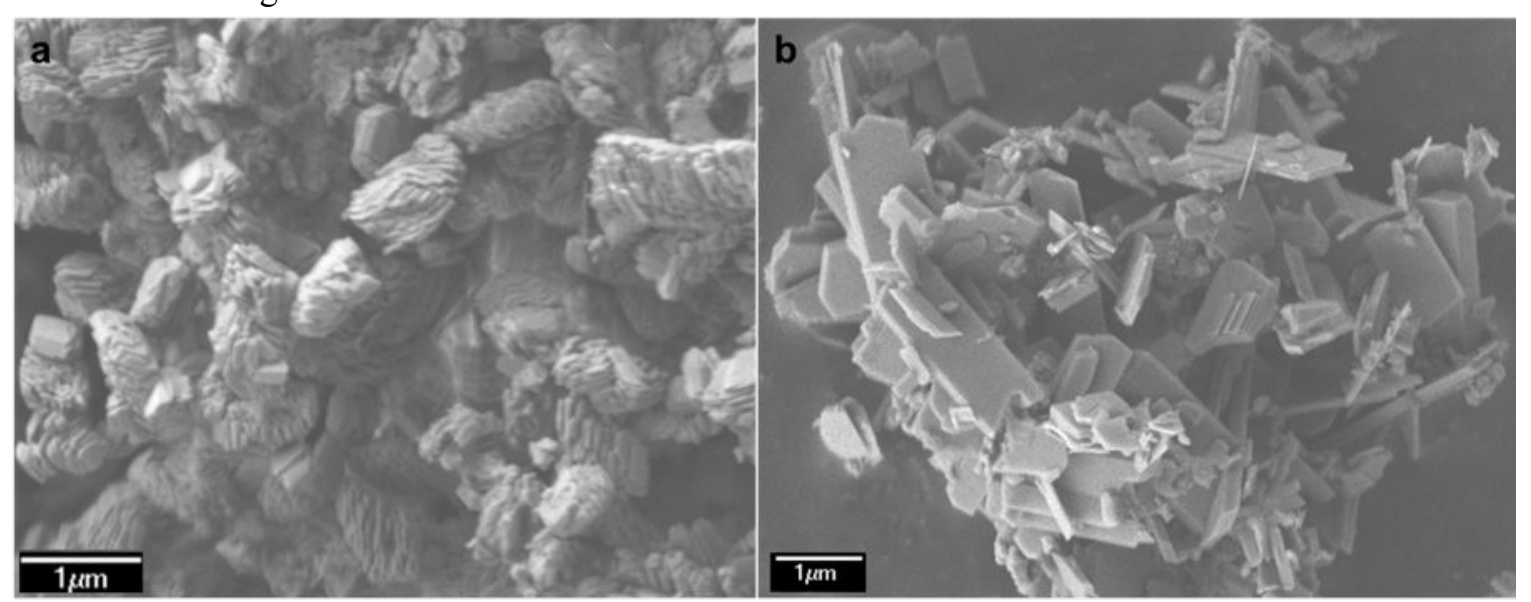

Figure S5. a) SEM image of as-made zeolite EMM-37 and b) SEM image of sample after calcination at $540{ }^{\circ} \mathrm{C}$.

The cRED data collection and the structure solution of EMM-37. The sample powder was crushed in an agate mortar, dispersed in an absolute ethanol and treated by ultrasonication for 2 minutes. Then, a droplet of the suspension was transferred onto a holey carbon film covered copper grid. The continuous rotation electron diffraction (cRED) data were collected using a JEOL JEM-2100 transmission electron microscope (TEM) operated at $200 \mathrm{kV}$ using a single-tilt tomography holder. The cRED data were collected by continuously tilting the goniometer, video mode of data collection was registered using SoPhy software and high-speed hybrid detection camera Timepix Quad. Collected datasets were processed and merged using Xray Detector Software (XDS), which generated the $h k l$ files that were used for structure solution and refinement. The structure of EMM-37 was solved using software SIR2014 and the refinement was done using SHELXL-97. Two Datasets were collected for as-made EMM-37 (see Table S1) and 6 datasets were collected for sample after calcination at $540^{\circ} \mathrm{C}$ (see Table S2). In both cases the final structure solution and refinement were done using merged data. 
Table S1. Continuous rotation electron diffraction data collection and structure refinement details of asmade EMM-37.

$\begin{array}{llll}\text { Crystal system } & \begin{array}{l}\text { Dataset } 1 \\ \text { Triclinic }\end{array} & \begin{array}{l}\text { Dataset } 2 \\ \text { Triclinic }\end{array} & \begin{array}{l}\text { Merged data } \\ \text { Triclinic }\end{array} \\ \text { Space group (No.) } & P-1(2) & P-1(2) & P-1(2) \\ a, \AA & 9.03 & 8.91 & 8.8317^{*} \\ b, \AA & 9.84 & 9.96 & 9.6347^{*} \\ c, \AA & 10.81 & 10.91 & 10.652^{*} \\ \alpha,{ }^{\circ} & 104.2 & 104.7 & 104.4^{*} \\ \beta,^{\circ} & 98.6 & 100.0 & 99.8^{*} \\ \gamma^{\circ} & 99.6 & 98.6 & 99.5^{*} \\ \text { Volume, } \AA^{3} & 899.7 & 903.0 & 844.4 \\ \lambda, \AA & 0.0251 & 0.0251 & 0.0251 \\ \text { Tilt range }\left({ }^{\circ}\right) & -50.9 \text { to }+59.3 & -51.7 \text { to }+65.8 & \\ \text { No. cRED frames } & 480 & 511 & \\ \text { Tilt step per frame }\left({ }^{\circ}\right) & 0.23 & 0.23 & 0.23 \\ \text { Exposure time per frame (s) } & 0.5 & 0.5 & 0.5 \\ \text { Completeness, } \% & 60.6 & 63.7 & 79.8 \\ \text { No. refined parameters } & 191 & 191 & 191 \\ \text { Resolution, } \AA & 0.70 & 0.70 & 0.70 \\ \text { No. restraints } & 0 & 20 & 0 \\ \mathrm{R}_{\text {int }} & 0.118 & 0.157 & 0.261 \\ \text { No. symmetry independent reflections } & 3307 & 3478 & 4324 \\ \mathrm{R}_{1} & 0.254 & 0.352 & 0.299 \\ \text { wR }_{2} & 0.515 & 0.591 & 0.580 \\ \text { GooF } & 1.35 & 1.08 & 1.26\end{array}$

Unit cell parameters from Rietveld refinement are used for the merged data. 
Table S2. Continuous rotation electron diffraction data collection and structure refinement details of calcined EMM-37.

\begin{tabular}{|c|c|c|c|c|c|c|c|}
\hline & Dataset 1 & Dataset 2 & Dataset 3 & Dataset 4 & Dataset 5 & Dataset 6 & $\begin{array}{l}\text { Merged } \\
\text { data }\end{array}$ \\
\hline Crystal system & Triclinic & Triclinic & Triclinic & Triclinic & Triclinic & Triclinic & Triclinic \\
\hline Space group & $P-1(2)$ & $P-1(2)$ & $P-1(2)$ & $P-1(2)$ & $P-1(2)$ & $P-1(2)$ & $P-1(2)$ \\
\hline$a, \AA$ & 8.96 & 9.03 & 8.96 & 8.97 & 9.09 & 8.78 & $8.7318^{\dagger}$ \\
\hline$b, \AA$ & 10.11 & 9.59 & 10.02 & 10.05 & 10.13 & 9.81 & $9.6171^{\dagger}$ \\
\hline$c, \AA$ & 10.78 & 10.66 & 10.68 & 10.86 & 10.78 & 10.51 & $10.464^{\dagger}$ \\
\hline$\alpha,{ }^{o}$ & 105.7 & 106.0 & 105.4 & 104.2 & 108.0 & 106.2 & $104.81^{\dagger}$ \\
\hline$\beta,^{\circ}$ & 100.5 & 101.7 & 99.6 & 100.7 & 99.3 & 99.8 & $99.749^{\dagger}$ \\
\hline$\gamma,{ }^{\circ}$ & 97.4 & 97.0 & 98.2 & 96.4 & 96.4 & 96.1 & $98.822^{\dagger}$ \\
\hline Volume, $\AA^{3}$ & 907.83 & 853.30 & 893.68 & 919.84 & 917.77 & 845.23 & 819.25 \\
\hline$\lambda, \AA$ & 0.0251 & 0.0251 & 0.0251 & 0.0251 & 0.0251 & 0.0251 & 0.0251 \\
\hline Tilt range $\left({ }^{\circ}\right)$ & $\begin{array}{l}-49.7 \text { to }- \\
1.61\end{array}$ & $\begin{array}{l}-32.5 \text { to } \\
+17.4\end{array}$ & $\begin{array}{l}-48.9 \text { to } \\
+1.24\end{array}$ & $\begin{array}{l}-47.7 \text { to } \\
+3.36\end{array}$ & $\begin{array}{l}-51.4 \text { to }- \\
1.03\end{array}$ & $\begin{array}{l}-52.7 \text { to } \\
+52.64\end{array}$ & \\
\hline No. cRED frames & 210 & 218 & 219 & 223 & 220 & 459 & \\
\hline $\begin{array}{l}\text { Tilt range per } \\
\text { frame }\left(^{\circ}\right)\end{array}$ & 0.23 & 0.23 & 0.23 & 0.23 & 0.23 & 0.23 & 0.23 \\
\hline $\begin{array}{l}\text { Exposure time per } \\
\text { frame }(s)\end{array}$ & 0.5 & 0.5 & 0.5 & 0.5 & 0.5 & 0.5 & 0.5 \\
\hline Completeness, \% & 25.9 & 26.6 & 25.5 & 27.7 & 27.0 & 53.6 & 88.7 \\
\hline No. parameters & 191 & 191 & 191 & 191 & 191 & 191 & 191 \\
\hline Resolution, §̊ & 0.7 & 0.7 & 0.7 & 0.7 & 0.7 & 0.7 & 0.7 \\
\hline No. restraints & 102 & 24 & 36 & 48 & 120 & 6 & 0 \\
\hline $\mathrm{R}_{\text {int }}$ & 0.082 & 0.072 & 0.063 & 0.067 & 0.056 & 0.078 & 0.189 \\
\hline $\begin{array}{l}\text { No. symmetry } \\
\text { independent } \\
\text { reflections }\end{array}$ & 1435 & 1386 & 1392 & 1554 & 1513 & 2764 & 4419 \\
\hline $\mathrm{R}_{1}$ & 0.204 & 0.180 & 0.212 & 0.228 & 0.333 & 0.212 & 0.224 \\
\hline$w_{2}$ & 0.470 & 0.419 & 0.489 & 0.488 & 0.647 & 0.507 & 0.490 \\
\hline GooF & 1.68 & 1.47 & 1.94 & 1.75 & 2.68 & 2.08 & 1.60 \\
\hline
\end{tabular}

a

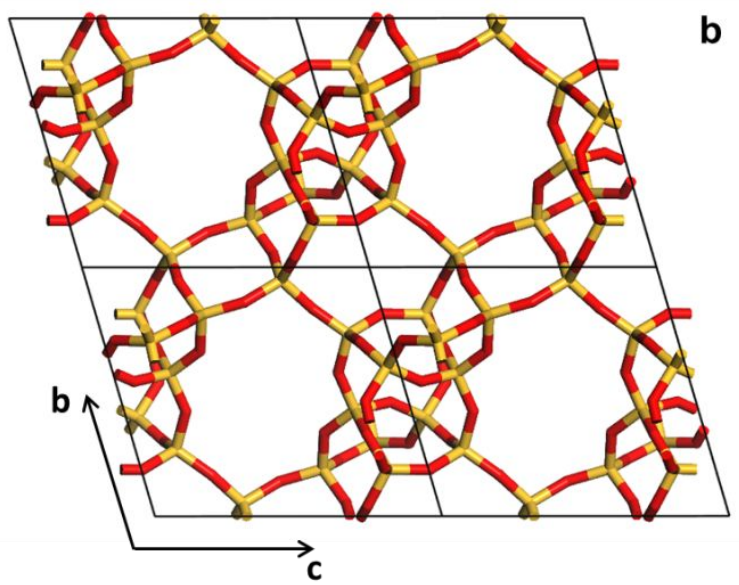

b

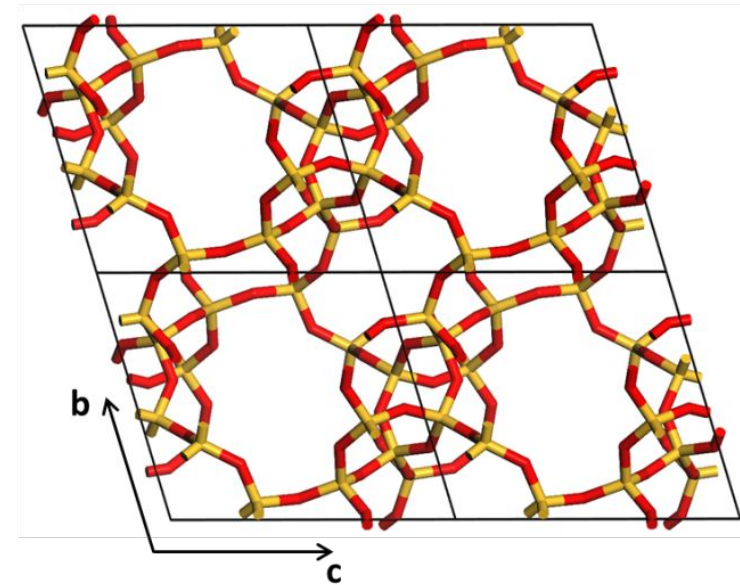

Figure S6. The structure of EMM-37 viewed along [100] for a) as-made and b) calcined sample. 
Table S3. Difference of T and O atomic positions for as-made and calcined samples.

\begin{tabular}{cc|cc}
\multicolumn{3}{c}{ Difference, $\AA$} & \multicolumn{2}{c}{ Difference, $\AA$} \\
\hline T1 & 0.328 & O1 & 0.301 \\
T2 & 0.463 & O2 & 0.507 \\
T3 & 0.299 & O3 & 0.623 \\
T4 & 0.518 & O4 & 0.275 \\
T5 & 0.221 & O5 & 0.632 \\
T6 & 0.151 & O6 & 0.512 \\
T7 & 0.382 & O7 & 0.222 \\
\cline { 1 - 1 } Min & $\mathbf{0 . 1 5}$ & O8 & 0.095 \\
Max & $\mathbf{0 . 5 2}$ & O9 & 0.404 \\
Average & $\mathbf{0 . 3 4}$ & O10 & 0.455 \\
& & O11 & 0.475 \\
& & O12 & 0.715 \\
& & O13 & 0.409 \\
& & O14 & 0.351 \\
\cline { 3 - 3 } & & Min & $\mathbf{0 . 1 0}$ \\
& & Max & $\mathbf{0 . 7 2}$
\end{tabular}

\section{Rietveld refinement of as-made EMM-37 against synchrotron data.}

The Rietveld refinement of the as-made EMM-37 was performed with GSAS. An as-made sample of EMM37 was packed and then flame-sealed into a $0.5 \mathrm{~mm}$ quartz capillary. Data were collected at beamline 11-BM at Argonne National Laboratory under ambient temperature in Debye-Scherrer mode with a wavelength of $0.457656 \AA$ over a range of $2^{\circ}$ to $30^{\circ}$ two theta with a step length of $0.001^{\circ} 2$ theta. Initially a LeBail fit was performed to optimize the unit cell dimensions, background, and peak profile. The background was modeled with a 20-term shifted Chebyshev polynomial, and the peak profile was modeled with the peak-shape function of P. Thompson, D.E. Cox \& J.B. Hastings ${ }^{3}$ with the asymmetry correction as described in the reference. ${ }^{4}$ Terms were included for broadening due to anisotropic crystal size and strain.

Data were used to a d-spacing of $0.8645 \AA$ for a total of 2732 reflections. There are 84 refined fractional coordinates, three isotropic thermal factors, and six refined unit cell parameters.

In the initial stages of the refinement, restraints were placed on the T-O distances $(1.635+/-0.025 \AA)$, the O-O tetrahedral distances $(2.67+/-0.025 \AA 0.03)$, the $\mathrm{C}-\mathrm{C}$ or $\mathrm{C}-\mathrm{N}$ distances of nearest carbon and/or nitrogen atoms $(1.54+/-0.03 \AA)$, and the $\mathrm{C}-\mathrm{C}$ or $\mathrm{C}-\mathrm{N}$ distances of next nearest carbon and/or nitrogen atoms $(2.50+/-$ $0.04 \AA$ ). The $\mathrm{T}$ atoms were constrained to have identical isotropic thermal parameters as were the $\mathrm{O}$ atoms and the $\mathrm{C} / \mathrm{N}$ atoms of the organic molecule. During this early stage of the refinement a forcing factor of 5 for distance restraints. The scattering factors for $\mathrm{CH}_{2}, \mathrm{CH}_{3}$, and $\mathrm{N}$ species of the organic molecule were approximated with the scattering factor an $\mathrm{O}$ atom. All $\mathrm{T}$ atoms were modeled with silicon. For computations, the EMM-37 unit cell was optimized using Density Functional Theory (DFT). The SDA was fit into the EMM-37 unit cell by random insertions and a distance-based acceptance scheme. The zeolite unit cell was then re-optimized using DFT. All DFT calculations were performed using the CP2K quantum chemistry package. A PBE functional was used, with a double-zeta polarizable (DZP) all-atom basis set, and $800 \mathrm{eV}$ plane-wave cutoff. Dispersion interactions were included using the D3 approximation. In the energyoptimized configuration, the inversion center of the SDA molecule was very close to that of the unit cell at $(0,1 / 2,1 / 2)$. In order to minimize the number of refined parameters of the organic SDA, we fixed the inversion center of the organic molecule upon this inversion center. This reduces the number of refined organic atoms from 14 to 7. During the refinement cycles, the molecule rotated from its initial position. This resulted in a 
decrease of more than $1 \%$ in the $\mathrm{R}$ factors. This indicates that the refined position of the molecule is a good approximation to the actual configuration of the molecule within the zeolite. Figures S7 compare the initial and refined configurations of the SDA along different projections. After the initial refinement of the framework and extra framework atoms, the restraints were completely relaxed. Although a simple model is used for the organic molecule, excellent agreement is obtained between the diffraction patterns of the experimental data and the simulated data for the model. In the final stages, the unit cell dimensions, background, and peak profile were further refined. The Rp, Rwp, and $\chi^{2}$ were $5.16 \%, 6.52 \%$, and 1.03 , respectively, see Figure S8 for the visual fit. Tables S5 summarizes the bond geometries of the refined framework. The long average Si3-O bond length $(1.65 \AA)$ suggests that T3 may be a preferred location for aluminum. T7 may also be a preferred site for aluminum.

Table S4. The details of Rietveld refinement of zeolite EMM-37.

$\begin{array}{ll}\text { Crystal system } & \text { Triclinic } \\ \text { Space group } & P-1 \text { (No. 2) } \\ a, \AA & 8.8317 \\ b, \AA & 9.6347 \\ c, \AA & 10.652 \\ \alpha,{ }^{\circ} & 104.410 \\ \beta,{ }^{\circ} & 99.799 \\ \gamma,{ }^{\circ} & 99.499 \\ {\text { Volume, } \AA^{3}}_{\lambda, \AA}{ }^{3} & 844.36 \\ \text { Temperature, }{ }^{\circ} \mathrm{C} & 0.457656 \\ 2 \text { Theta range, } & 20 \\ \text { Resolution, } \AA & 2-30 \\ \text { No. reflections }^{\circ} & 0.8645 \\ \mathrm{R}_{\mathrm{wp}} & 2732 \\ \mathrm{R}_{\mathrm{p}} & 0.0652 \\ \mathrm{GoF} & 0.0516 \\ & 1.03\end{array}$




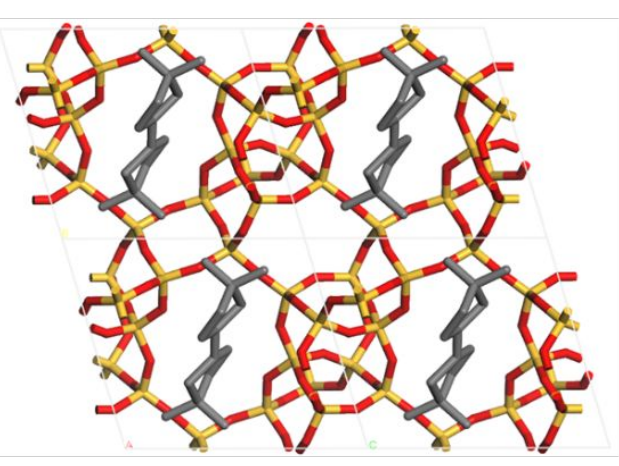

Refined Model

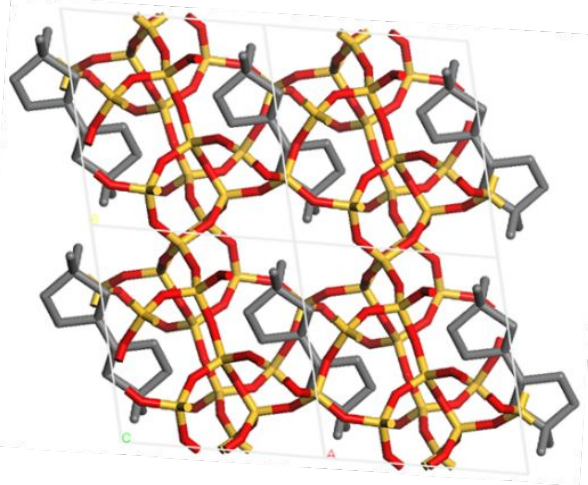

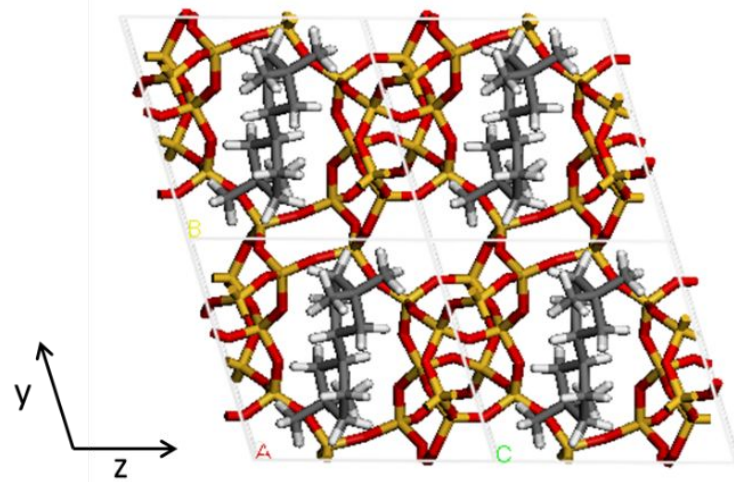

Starting Model

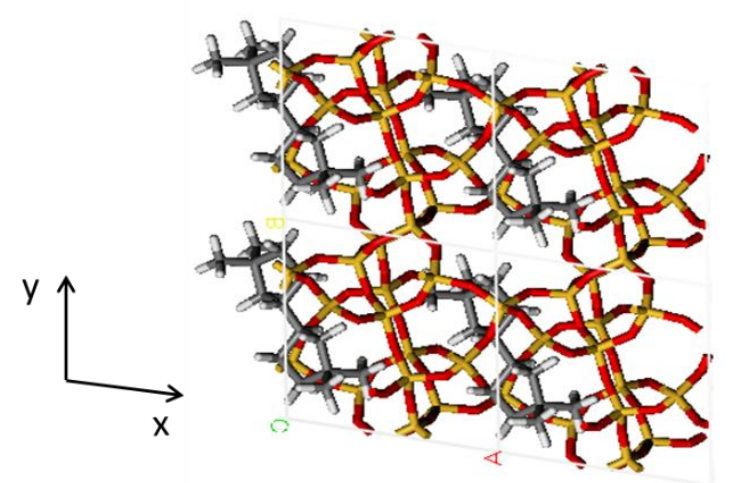

Figure S7. Structure model showing the position of the SDA molecule in the starting model (right) and the position after Rietveld refinement (left).

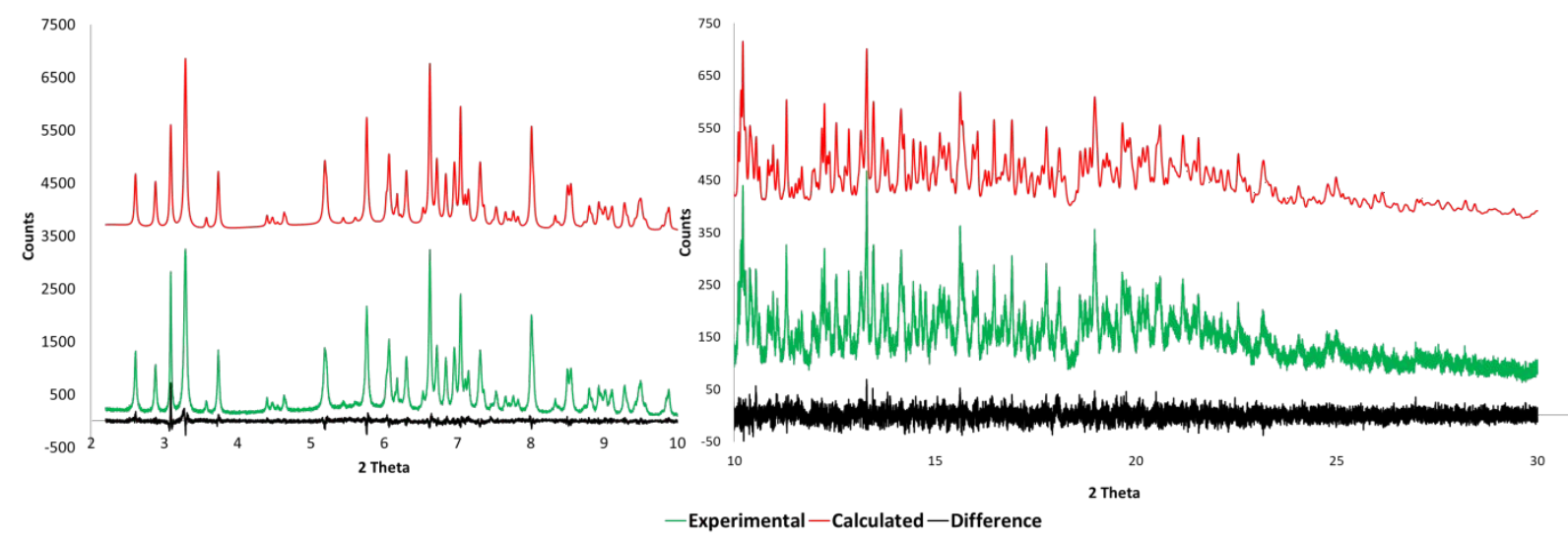

Figure S8. Plots of the Rietveld refinement of the as-made EMM-37. Calculated intensities on top (red), observed (green) in the middle and difference (black) at the bottom. The region from $10-30^{\circ}$ is enlarged. 
Table S5. The bond distances and O-T-O angles for the framework atoms after Rietveld refinement.

\begin{tabular}{|c|c|c|c|c|c|}
\hline \multicolumn{6}{|c|}{$\begin{array}{l}\text { Bond } \\
\text { Distances }(\AA)\end{array}$} \\
\hline Si1-01 & 1.572 & Si4-O3 & 1.595 & Si7-O2 & 1.603 \\
\hline S1-O5 & 1.619 & Si4-06 & 1.600 & Si7-08 & 1.672 \\
\hline Si1-07 & 1.629 & Si4-010 & 1.610 & Si7-013 & 1.649 \\
\hline Si1-08 & 1.581 & Si4-012 & 1.660 & Si7-014 & 1.617 \\
\hline$<\mathrm{Si1}-\mathrm{O}>$ & 1.600 & $<\mathrm{Si} 4-\mathrm{O}\rangle$ & 1.616 & $<\mathrm{Si} 7-\mathrm{O}\rangle$ & 1.635 \\
\hline $\mathrm{Si2-O} 2$ & 1.580 & Si5-04 & 1.616 & T-O-T angles & \\
\hline $\mathrm{Si} 2-\mathrm{O} 4$ & 1.612 & Si5-O5 & 1.613 & Si1-O1-Si3 & 157.7 \\
\hline Si2-O7 & 1.651 & Si5-09 & 1.651 & $\mathrm{Si2-O2-Si7}$ & 153.1 \\
\hline Si2-012 & 1.630 & Si5-011 & 1.587 & Si3-O3-Si4 & 152.1 \\
\hline \multirow[t]{3}{*}{$<\mathrm{Si} 2-\mathrm{O}\rangle$} & 1.618 & $<\mathrm{Si5}-\mathrm{O}\rangle$ & 1.617 & Si2-O4-Si5 & 148.5 \\
\hline & & & & Si1-05-Si5 & 149.7 \\
\hline & & & & Si4-06-Si6 & 146.3 \\
\hline Si3-01 & 1.684 & Si6-06 & 1.635 & Si1-07-Si2 & 143.5 \\
\hline Si3-O3 & 1.661 & Si6-09 & 1.573 & Si1-08-Si7 & 141.5 \\
\hline Si3-010 & 1.618 & Si6-013 & 1.613 & Si5-09-Si6 & 147.1 \\
\hline Si3-011 & 1.641 & Si6-014 & 1.639 & Si3-010-Si4 & 154.4 \\
\hline \multirow[t]{3}{*}{$\langle\mathrm{Si3}-\mathrm{O}\rangle$} & 1.651 & $\langle\mathrm{Si6}-\mathrm{O}\rangle$ & 1.615 & Si3-011-Si5 & 142.2 \\
\hline & & & & Si2-O12-Si4 & 135.3 \\
\hline & & & & Si6-013-Si7 & 135.4 \\
\hline \multicolumn{6}{|l|}{$\begin{array}{l}\text { Tetrahedral } \\
\text { Angles }\left({ }^{\circ}\right)\end{array}$} \\
\hline O1-Si1-O5 & 107.5 & O3-Si4-06 & 108.7 & 02-Si7-08 & 109.7 \\
\hline O1-Si1-07 & 107.5 & O3-Si4-010 & 108.1 & 02-Si7-013 & 110.5 \\
\hline O1-Si1-08 & 110.5 & O3-Si4-012 & 109.7 & O2-Si7-014 & 110.6 \\
\hline O5-Si1-O7 & 107.9 & O6-Si4-010 & 109.9 & 08-Si7-013 & 108.1 \\
\hline O5-Si1-08 & 111.3 & O6-Si4-012 & 111.3 & 08-Si7-014 & 108.5 \\
\hline O7-Si1-08 & 112.0 & O10-Si4-012 & 109.1 & O13-Si7-014 & 109.4 \\
\hline$<0-S i 1-O>$ & 109.5 & $<\mathrm{O}-\mathrm{Si} 4-\mathrm{O}\rangle$ & 109.5 & $<0-S i 7-O>$ & 109.5 \\
\hline O2-Si2-O4 & 112.5 & O4-Si5-O5 & 111.1 & & \\
\hline O2-Si2-O7 & 108.2 & O4-Si5-09 & 107.2 & & \\
\hline O2-Si2-O12 & 111.2 & O4-Si5-011 & 110.1 & & \\
\hline O4-Si2-O7 & 111.2 & O5-Si5-09 & 112.8 & & \\
\hline O4-Si2-012 & 106.0 & O5-Si5-011 & 108.3 & & \\
\hline 07-Si2-012 & 107.6 & 09-Si5-011 & 107.3 & & \\
\hline$<\mathrm{O}-\mathrm{Si} 2-\mathrm{O}\rangle$ & 109.5 & $<\mathrm{O}-\mathrm{Si} 5-\mathrm{O}>$ & 109.5 & & \\
\hline O1-Si3-O3 & 105.9 & 06-Si6-09 & 107.7 & & \\
\hline 01-Si3-010 & 113.5 & O6-Si6-013 & 107.2 & & \\
\hline
\end{tabular}




\begin{tabular}{|l|l|l|l|l|l|}
\hline O1-Si3-011 & 107.4 & O6-Si6-O14 & 108.5 & \\
\hline O3-Si3-010 & 108.4 & O9-Si6-O13 & 111.1 & \\
\hline O3-Si3-011 & 113.7 & O9-Si6-O14 & 110.4 & \\
\hline O10-Si3-O11 & 108.2 & O13-Si6-O14 & 111.9 & \\
\hline$<$ O-Si3-O> & 109.5 & <-Si6-O> & 109.5 & \\
\hline
\end{tabular}
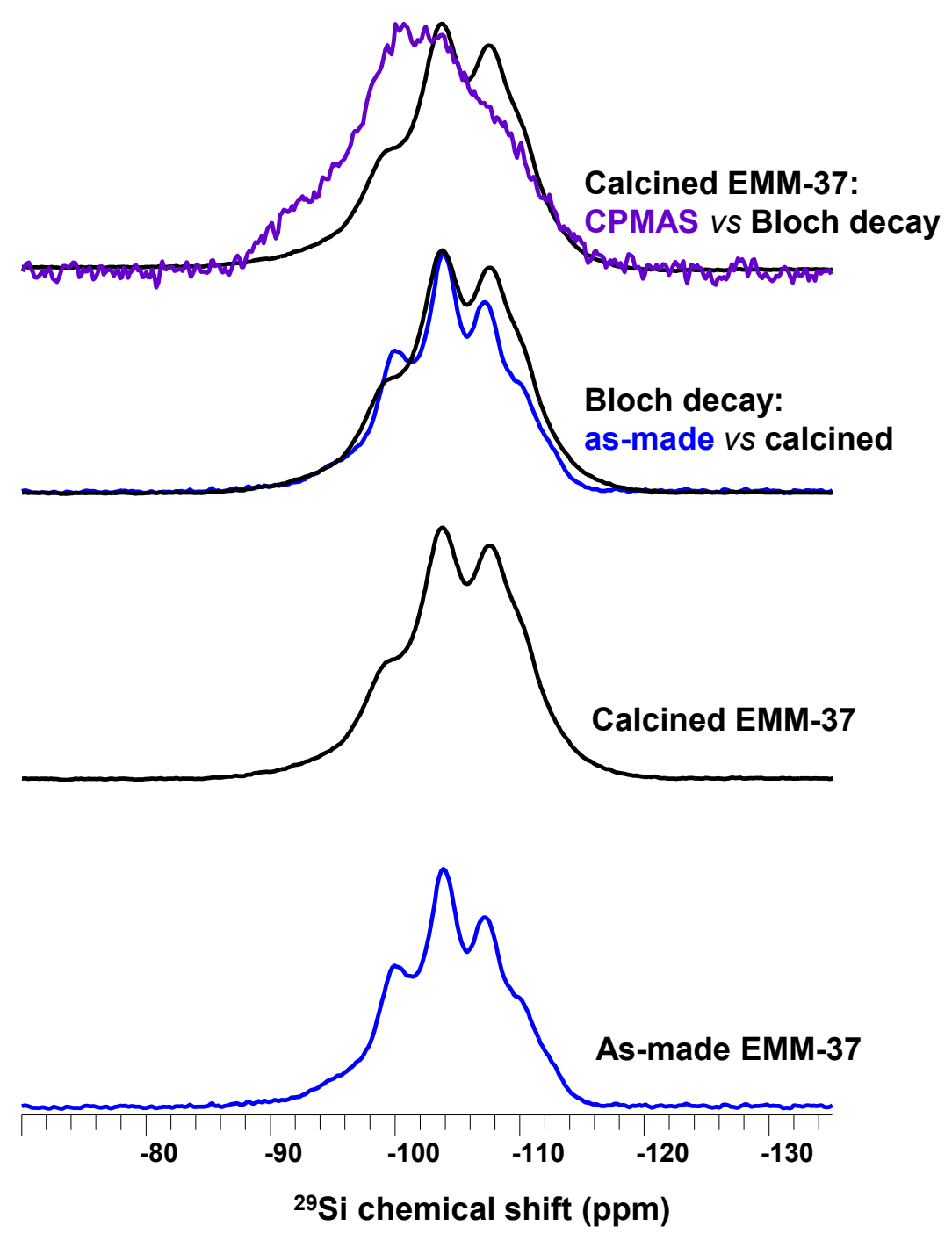

Figure S9. ${ }^{29}$ Si MAS NMR spectra of as-made (bottom) and calcined (second from bottom) EMM-37. Superimposed MAS NMR spectra of as-made vs calcined samples and CPMAS vs. MAS (Bloch decay) NMR spectra of the calcined sample (top) are shown as well. 

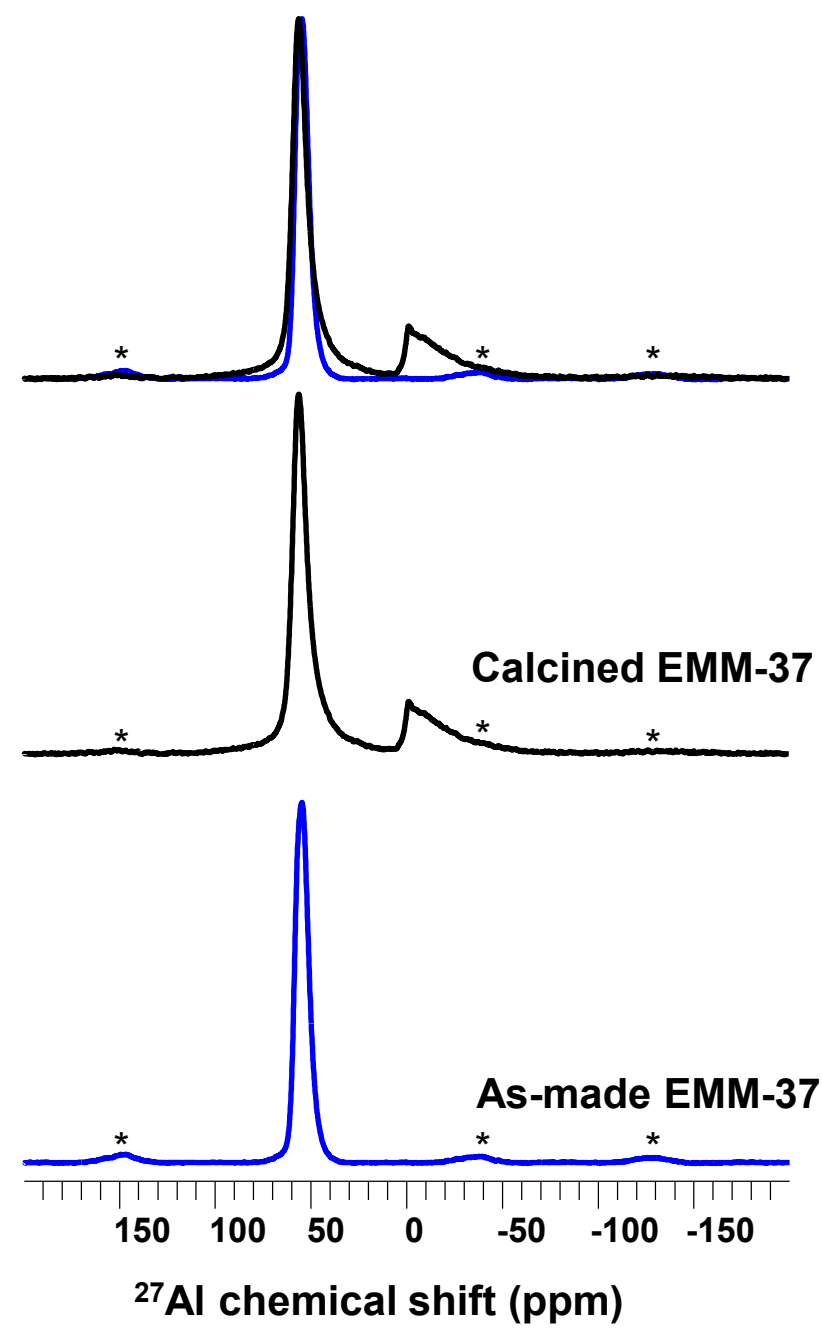

Figure S10. ${ }^{27} \mathrm{Al}$ MAS NMR of as-made (bottom), calcined (middle), superimposed spectra of the two (top) EMM-37. Asterisks represent spinning sidebands.
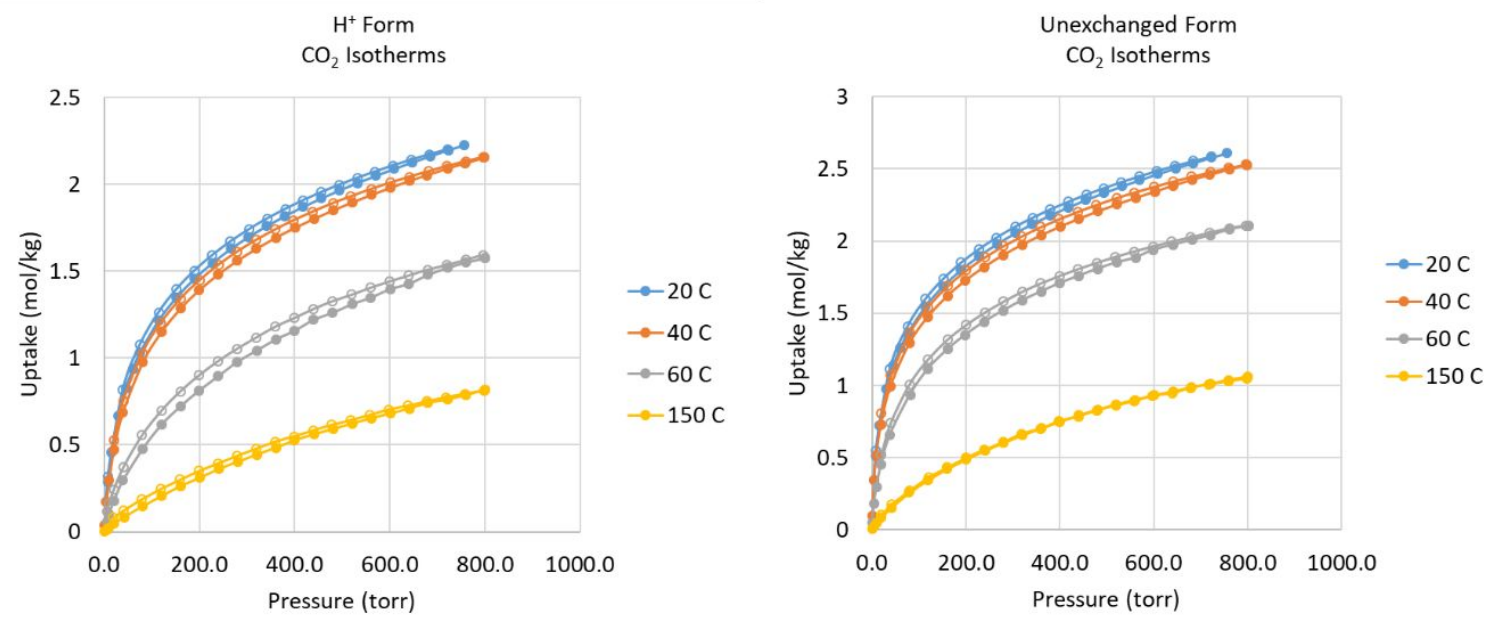

Figure S11. $\mathrm{CO}_{2}$ sorption isotherms in the proton and unexchanged forms of EMM-37. The solid symbols are adsorption points and the hollow symbols are desorption points. 

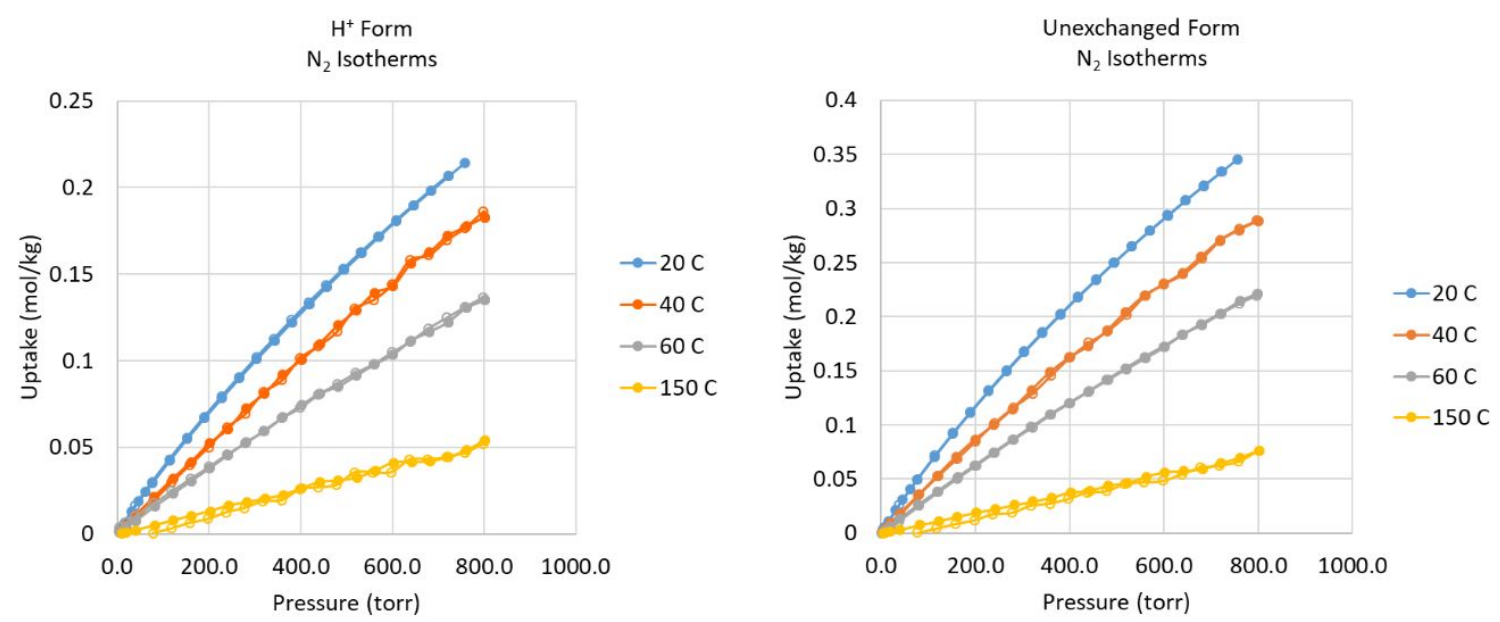

Figure S12. $\mathrm{N}_{2}$ sorption isotherms for the proton and unexchanged forms of EMM-37. The solid symbols are adsorption points and the hollow symbols are desorption points.
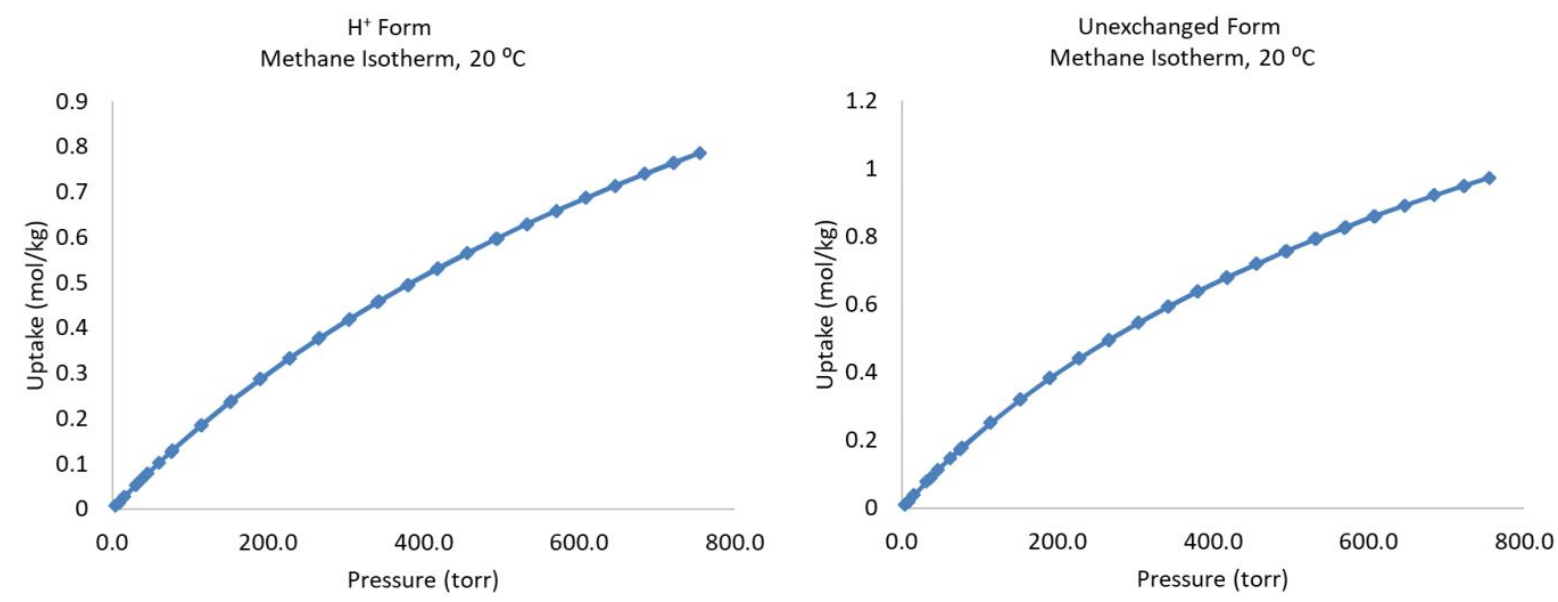

Figure S13. $\mathrm{CH}_{4}$ sorption isotherms for the proton and unexchanged forms of EMM-37. 
Figure S14 shows Grand Canonical Monte Carlo molecular simulations of adsorption isotherms of $\mathrm{CO}_{2}, \mathrm{CH}_{4}$ and $\mathrm{N}_{2}$ in the pure-silica framework of EMM-37. Molecular interactions were modeled using two different forcefields from the literature. Since interactions with pure-silica form of zeolites are less strong for all the molecules, the isotherms are less sharp compared to the experimental measurements on aluminosilicate forms of EMM-37. However, the total capacity of the material for $\mathrm{CO}_{2}$ is very close to the experimental measurement. Figure S15 shows representative snapshots from molecular simulations.

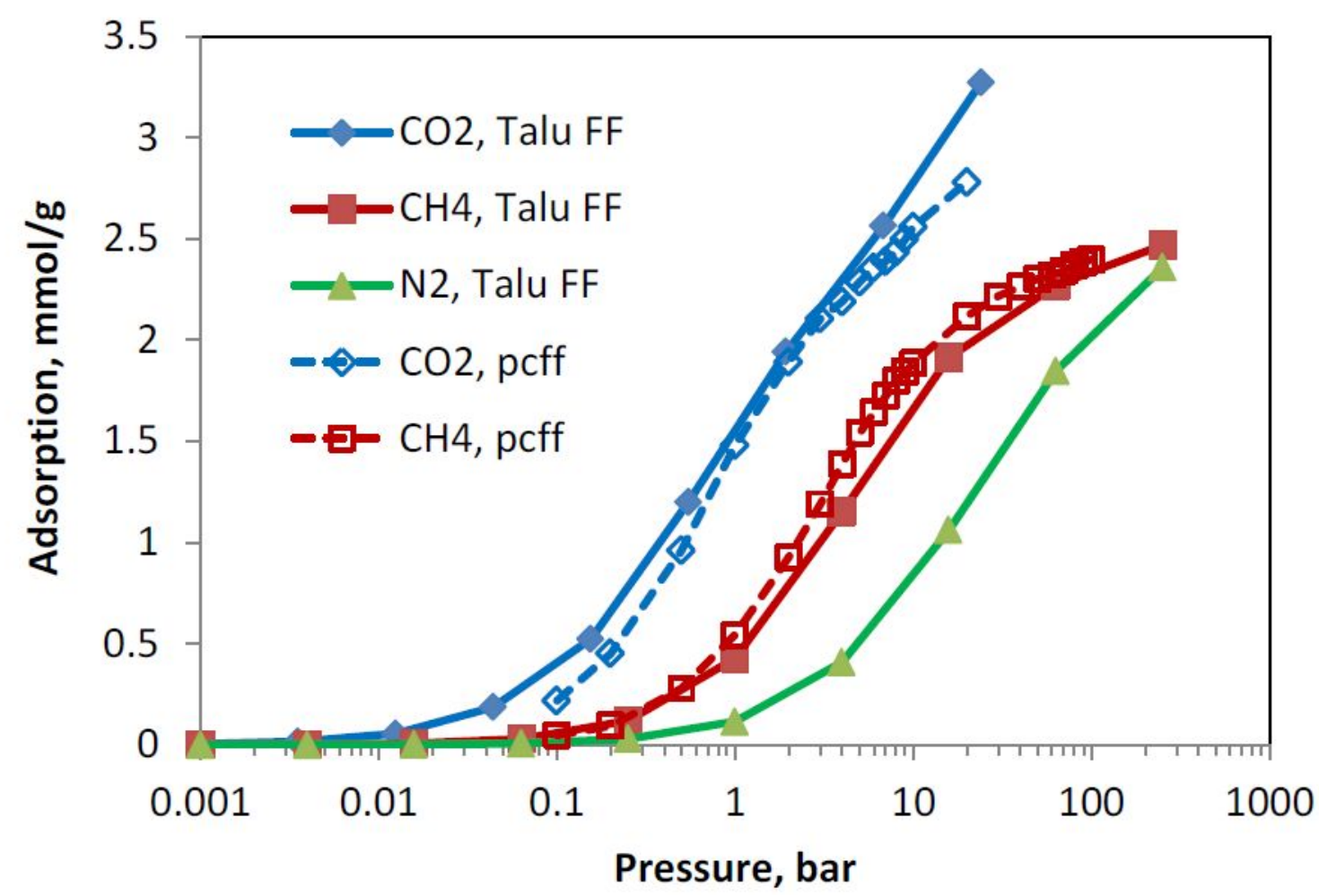

Figure S14. Simulated carbon dioxide, methane and nitrogen adsorption isotherms at $300 \mathrm{~K}$ on pure silica EMM-37 using Talu and pcff force fields.
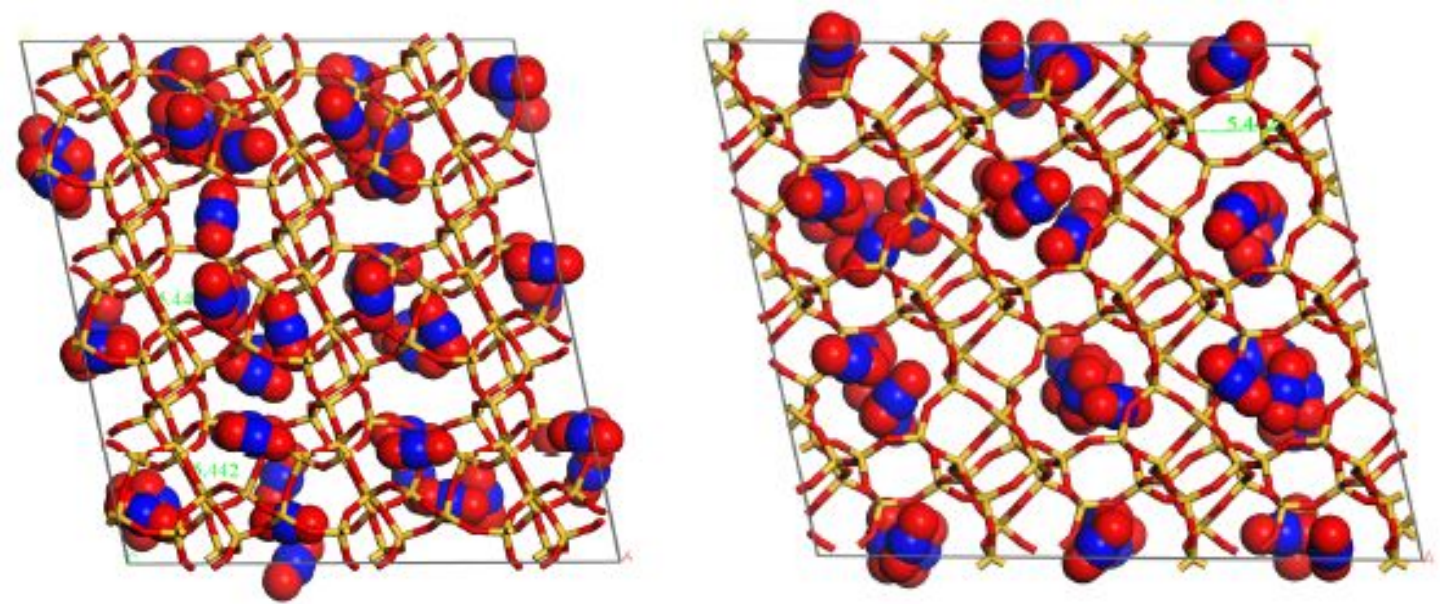

Figure S15. Snapshots of $\mathrm{CO}_{2}$ molecules adsorbed in silica EMM-37 at $2.4 \mathrm{mmol} / \mathrm{g}$ loading. 


\section{References}

1. Murari, R., Baumann, W. J. Quadrupolar carbon-13-nitrogen-14 couplings and nitrogen-14 relaxations in aggregated and nonaggregated choline phospholipids. J. Am. Chem. Soc. 103, 1238-1240 (1981).

2. Olivieri, A. C., Frydman, L., Grasselli, M., Diaz, L. E. Analysis of ${ }^{13} \mathrm{C},{ }^{14} \mathrm{~N}$ residual dipolar coupling in the 13C CP/MAS NMR spectra of ribonucleosides. Magn. Reson. in Chem., 26, 281- 286 (1988).

3. Thompson, P., Cox, D.E., Hastings, J.B. Rietveld Refinement of Debye-Scherrer synchrotron x-ray data from $\mathrm{Al}_{2} \mathrm{O}_{3}$. J. Appl. Cryst. 20, 79-83 (1987).

4. Finger, L.W., Cox, D.E., Jephcoat, A. P. A correction for powder diffraction peak asymmetry due to axial divergence. J. Appl. Cryst. 27, 892-900 (1994). 